\title{
To truly 'live’, urban design needs accessible interdisciplinary research
}

\author{
Matthew Carmona \\ The Bartlett School of Planning, UCL \\ m.carmona@ucl.ac.uk
}

I was honoured to feature in the first issue of the Journal of Urban Design some 25 years ago, and it has remained my journal of choice ever since. Today it is one of the foundations of urban design scholarship.

But why is research in urban design important? If research in a subject does not seem important, then either we already know (or think we know) all there is to know about it, or we believe it to be so unimportant that it doesn't justify the time and effort required to find out more. Such subjects are 'dead' or at least moribund as they have stopped developing. By contrast, for a discipline to live and prosper it needs a viable, indeed thriving, research base. The Journal of Urban Design is a key part of the infrastructure that makes this possible. Without it, the subject - theoretically, practically, methodologically and in its influence, would be immeasurably the poorer.

\section{The challenges of urban design research}

As we know, the built environment is a notoriously siloed field of professional and academic endeavour. Yet it is in the realm of urban design where many remits meet: the land use mixes determined by planning, the space defining nature of architecture, the social impact of infrastructure engineering, the ecological concern of landscape design, and so forth. As an arena for research, urban design should be both multidisciplinary, in the sense that it is practiced (and researched) by professionals from different backgrounds; and interdisciplinary, in the sense that through engagement with complex urban problems from contrasting disciplinary perspectives, new knowledge can be generated and then shared. This involves reaching beyond lone disciplines to address the sorts of 'wicked' problems that characterise urban design, and reaching outside our comfort zones as 
researchers to select and combine the best methodological approaches for each urban problem. Combining social science methods with 'designerly ways of knowing' and science-based analytics

Unfortunately, not every subject amongst the many hundreds of academic disciplines listed in Wikipedia ${ }^{1}$ offers the same research opportunities. In the UK, for example, the five research councils dealing with science and medical research together have roughly ten times as much budget as the two that deal with arts, humanities and social sciences (within which funded research on urban design often fits).

In part this reflects how society (and the market) values knowledge in different areas, but it also reflects the nature of the problems being investigated, how established a discipline is, and perceptions of the potential impact of research in that arena. Of course medical and scientific research is comparatively expensive to conduct, requiring long time frames and expensive equipment, but there is also an element of the unknown with much non-science research:

- First, the questions being asked are often not straightforward, they are difficult to identify and frame, let alone address. As Marshall (2012: 268) puts it: 'Cities are not rocket science - they are more complex than that'.

- Second, the processes being examined typically focus on the vagaries of human actions and are therefore subject to continual change and varied interpretation as, in essence, they are unpredictable and poorly understood (unlike the laws of physical science).

- Finally, even when answers are secured to such research problems, they simply represent a snapshot of experience that continues to vary from place to place and over time. Even when the research is done, there is not always a clear line to a product, policy or practice and therefore to impact, making funding harder to justify.

Urban design is of this nature, despite its sphere of interest - the public and private built environment - impacting profoundly, for better or for worse, on the estimated 4 billion people that live in cities. Moreover, as this number relentlessly rises, processes of urban growth and change also continue relentlessly, often on the basis of flawed and outmoded knowledge about the local and global 
influence of such change, and about the potential to do better: socially, economically and environmentally. Yet this potential value of urban design is poorly understood by politicians, the public and industry, in part because of the rather intangible nature of many of its impacts.

By way of an example, investing in an anti-obesity pill would seem to deliver a tangible and direct benefit from a single clearly defined product, with clear knock-on commercial benefits. By contrast, designing the built environment to encourage us to do more exercise and not to get over-weight in the first place, seems infinitely more complex, involving numerous interconnecting elements, diffused responsibilities, and difficult to trace impacts. It is difficult to make the case for research in such fields, let alone to get action once the research has been done.

Yet the benefits from a better designed built environment are potentially huge, as is the power of urban design research to understand it, and this, in part, explains why the discipline has continued to grow and prosper over the last 60 years, and most particularly over the last 25 . Despite the challenges, this has been a period of rapid growth of the discipline in universities, in academic journals spearheaded by the Journal of Urban Design - as a focus or sub-focus of learned groups and societies, and, as a subject for academic research, from Masters' dissertations, through $\mathrm{PhDs}$, to funded research programmes and research-based practice.

All these things are necessary to give credibility to a discipline, and their development will be gradual rather than rapid. In this respect, urban design has been in an evolutionary phase, emerging slowly into a mature discipline, with all the birthing pains (should it / should it not be a discrete discipline?; should we / should we not define it?; etc., etc.) that contemporary debates between commentators still reveal. But perhaps this is inevitable for what elsewhere I have termed a 'mongrel' discipline that, to truly live, has had to emerge from in and amongst the traditional territories of the far larger and longer established disciplines - professional and academic - that surround it (Carmona 2014).

\section{Making urban design research relevant?}

Because ultimately research is of little value unless it advances our knowledge of a particular discipline, by its very nature research should be 'cutting edge' in the sense that it is generating new knowledge or information about a subject. This, however, does not imply that every piece of research 
will be paradigm changing, or even immediately useful in practice. Instead, much research in urban design will reflect on particular dimensions of professional practice, policy or design, with a view to incrementally improving, although not totally recasting, them. Other research will be more purely academic in nature, perhaps adding to larger critiques of the urban situation, reconceptualising urban design in whole or part, or applying blue skies design thinking to a particular place or problematic.

Potential audiences for urban design research will hail from four key groups:

1. Other researchers, both in urban design and in cognate and non-cognate fields

2. Practitioners, ranging across the design and other built environment professions, and including those involved in financing, delivering and managing the urban environment

3. Policy makers, both professional and political, and the interest groups who influence them

4. The users of the urban environment, who ultimately are the recipients of any changes to the built environment, whether or not informed by research.

Research in urban design will be equally valid whether intended to directly inform practice or influence academic debates. Neither form of research is intellectually superior, although in all cases it is vital to think about what the potential impact of the work is likely to be. In this regard theoretical work will be most powerful if, perhaps over time, it also informs practice. Equally, practice-related research will be more rigorous and incisive if it draws from, and feeds back into wider academic debates.

Amongst other issues, how researchers express themselves is important. Urban design concerns real world issues of great relevance to society, so tying up arguments in jargon and opaque language will rarely help to get key messages across. To offer just two examples (neither from the Journal of Urban Design!), the first, arguing the case for a city of intense sensory stimulation, from the architectural end of the urban scholarship spectrum:

\footnotetext{
"Everything must communicate with everything. ... This is made possible by the smooth parametric differentiation of all urban and architectural / urban subsystems and by infusing further order via the employment of associative logics that correlate the different sub-systems in ways that make them representations of each other, facilitating
} 
inferences from the visible to the invisible or not yet visible. The urban dweller should be able to read and navigate the Parametric Metropolis just like the natives of the Amazon read and navigate their jungle".

The second, from the urban geographical end, critiques the impact of a contemporary street design trend on those with disabilities:

Shared space can be characterised as 'disembodied urban design' that fails to capture the complexity of corporeal form and the manifold interactions of bodies-in-space. The disembodied understanding of the interactions between bodies, space, and movement, propagated by shared space design, (re)produces both existential insecurity and ontological uncertainty amongst certain categories of users.

The danger is that such language (and the equivalent illegible graphic / computational representations used by some on the architectural wing of urban design scholarship) limits the impact of important research to a small body of those who are already 'in the know', whilst throwing up barriers to the vast majority who are not.

Rather than a barrier that is rarely crossed, the boundary between theory and application should be permeable and diffuse, allowing researchers and practitioners to cross one way and back again with relative ease. Ideally, so should the boundary between research and practice, with researchers thinking carefully about how to frame and disseminate their work in order that it informs key academic debates whilst also informing policy and practice. Language will be a key part of this, as will the vehicle chosen for dissemination. Publishing in high quality international refereed journals is vital to test the rigour and efficacy of research, but in the past such articles have not always been widely read by practitioners and policy makers, hence limiting the journey from ideas and evidence to impact. The increasing use of Open Access articles in refereed journals will go a long way to address this, but the further dissemination of work via professional and social media outlets will also be vital.

\section{The future}

Just as the practice of urban design is endlessly diverse and fascinating, so too is the subject as a research field. In a subject with design at its heart, it will be important to bear in mind that there is no single truth in urban design, i.e. no set of principles and prescriptions that will apply everywhere. 
Equally, there will be no single right answers (or right methodologies) in urban design research, even in the most purely scientific of its pursuits. Baxter et al. (2010: 14) have written that research "is a social activity, that can be powerfully affected by the researcher's own motivations, and values. It also takes place within a broader social context, within which politics and power relations influence what research is undertaken, how it is carried out, and whether it is reported and acted upon".

As researchers we can never entirely escape from the baggage that each of us brings to our research, or from the baggage that others bring when reading it. That said, I often feel that the best research begins (at least) from a neutral rather than overtly political, disciplinary or methodological stance. In the future I would hope that our efforts would be a little less siloed and a little more interdisciplinary; a little less obscured by jargon and a little more accessible to potential users; a little better understood and valued by society, and, as a consequence, a little better resourced. The Journal of Urban Design will remain central to delivering all of this.

To Taner, what a wonderful achievement, to the journal, here's to the next 25 years!

\section{References}

Baxter L, Hughes C and Tight M (2010) How to Research (4th edition), Maidenhead, Open University Press

Carmona M (2014) The Place-shaping Continuum: A Theory of Urban Design Process, Journal of Urban Design, 19(1): 2-36

Marshall S (2012) Science, Pseudo-science and Urban Design, Urban Design International, 17(4): 257 71

\footnotetext{
1 In the Wikipedia list of academic disciplines urban design is not listed as a standalone discipline, but is instead tacked on to 'Urban Planning' under the larger category of 'Architecture', within the meta-category of 'Applied arts' (http://en.wikipedia.org/wiki/List_of_academic_disciplines).
} 